\title{
Identifying types of mental health problems and aggression among security guards: Are they totally safe
}

\author{
Affizal Ahmad*, Nurul Hazrina Mazlan \\ Forensic Sciences Programme, School of Health Sciences, Universiti Sains Malaysia, Kelantan, Malaysia
}

Email address:

affizal@kb.usm.my(A.Ahmad), hazrina2402@yahoo.com(N. H. Mazlan)

\section{To cite this article:}

Affizal Ahmad, Nurul Hazrina Mazlan, Identifying types of Mental Health Problems and Aggression among Security Guards: Are they Totally Safe? Psychology and Behavioral Sciences. Vol. 2, No. 3, 2013, pp. 130-137. doi: 10.11648/j.pbs.20130203.18

\begin{abstract}
Security guards give service within several ranges of tasks. In the line of duty in various work settings, guards may be expected to maintain order and to detain criminal violators while appointed to a single property or placed on patrol for various sites or territories. Concisely, a security guard may encounter a variety of situations, locations, and behaviours. With such a heavy responsibility and important duties, it is very important to make sure that the security guards are mentally and behaviourally healthy and safe. Concerning these issues, this study aimed to identify types of mental health problem and aggression among security guards. In addition, association between mental health problems and aggression, and difference between male and female security guards in terms of mental health problems were examined. Self-report surveys were conducted among 300 security guards in data collection. The findings identified four subtypes of mental health problems: substance abuse, antisocial personality disorder, borderline personality disorder, and depression, experienced by the security guards. The security guards were also reported to be performing physical aggression, verbal aggression, anger, and hostility. Male and female security guards showed significant difference in occurrence of mental health problems. The association between the mental health problems and aggression were also found mostly significant. Concisely, prevalence of mental health problems and aggressive behaviours was identified among security guards. These findings suggest that people who work as security guards in the presence of mental health problems are not totally safe. The findings recommend a serious need for mental health problems assessment among security guards during the enrolment or whilst performing daily duties in order to ensure healthy and safe employer and the public as whole and safe workplace environment. The findings of this study are crucial for public awareness.
\end{abstract}

Keywords: Security guard, Mental health problems, Aggression

\section{Introduction}

Work-related violence is recognised as one of the most significant occupational hazards especially in the recent decade where incidence of violence at work is shown increasing. Due to increased awareness on this alarming problem [1], many studies have been conducted to explore its effects to the physical and psychological health of individuals including among employers [2-5]. Most studies focus on one type of profession such as nurse, healthcare practitioner, and rescue personnel, but little is known about security guard. Some other studies focus on violence against security guard $[1,6]$. Empirical research on the involvement of security guards in aggression and violence however is scarce.

Security guard is one of the fastest growing occupations worldwide [7-8]. Security guard is defined as a privately employed individual, usually uniformed, who is personally hired or paid to protect a defined area of property and people via various direct or indirect methods [8-10]. The range of duties includes monitoring, guiding, maintaining, and most importantly, preventing crimes [9]. The significant role of security guard highlights the importance to specifically study the population, particularly in exploring the risk factors leading to negative acts among security guards. In recent years, involvements of security guards in workplace violence in several incidents have been recorded, such as assault of civilian [7] and negligence during working [7] [11].

Violence at work, or also known as work-related violence, can be defined as any work-related incidents involving abuse, threat, or assault, which directly or indirectly jeopardise the safety, well-being, and health of an employee, as defined by the European Commission [12]. Security 
guard is one of the occupations with high risk to get involved in incidents at work such as violence and crime [7, 12]. The needs for public interaction when working $[1,12]$, as well as working pattern such as shift working hour and solitary work [12-14], contribute to increased risk of incident at work. In addition, presence of other risk factors may elicit the probability for incidents to occur.

Several factors can be suggested as contributing elements towards involvement of security guard in violence and crime. These include stress [15-16], mental health problems [17-19], and lack of social skill training [20]. Stress due to great working responsibility has been identified as a probable factor that affects work performance among a group of mentally ill security guards [21]. Among all professions that deal with extensive job stress, security guard shows the highest percentage $(65.7 \%)$ [22]. This stressful circumstance has been proved to induce negative mental health and mood instability [14, 17-18, 23]. Shift work is the common major source of stress in a particular job, which encompasses both occupational and personal stress for instances sleep disturbance, mood disturbance, and reduced personal health and family functioning [14, 19, 23-24]. Significant relationship between stress and various dimensions of mental health such as anxiety, depression, and somatic disorders have been identified. In addition, more severe mental health problems that may eventually trigger the act of violence and aggression [17, 25-26] may also arise.

Mental health is defined by the World Health Organisation as a state of well-being in which the individual realises one's own abilities, can cope with the normal life stresses, can work productively and fruitfully, and is able to make a contribution to the community [27]. Mental health problems on the other hand refer to a state of disruption in the mental health of a person, which is a common subject of study worldwide. However, specific research on mental health problems among security guard is scarce. According to previous studies on workplace violence [6-7, 17-18], three types of mental health problems have been suggested: substance abuse, personality disorder, and depression. Conventionally, substance abuse is likely to occur among those who have to stay awake at night, as well as a known coping method for stress. Personality disorders particularly antisocial and borderline personality disorder are two common subjects related to violent incident [28-29]. The third type of mental health problems i.e., depression, is a well-known outcome of stress [30] as well as a recognised risk for aggressiveness [31-32].

The effects of mental health problems towards the well-being of security guard are undoubtedly related to their job performance. Well-being simply refers to being healthy, happy, and comfortable. Involvement of security guard in violence and crime may suggest that there is a disturbance to their well-being at work and this could be related to any significant problems in their mental health. In addition, the tendency to engage in particular aggressive act may explain their misdemeanour. Therefore, the first objective of this study was to identify the types of mental health problem and aggressive behaviours among security guards. Subsequently, the association between mental health problems and aggressive behaviours was examined. In addition, the difference between male and female security guards in terms of mental health problems was explored.

\section{Method}

\subsection{Study Design and Participants}

A cross-sectional study design was adapted for the current study. The sampling frames were institutions in Peninsular Malaysia that required presence of security guards and these institutions included financial, education, healthcare, and commercial institutions. Security guards present at these institutions were the sampling population. The sampling method was convenience sampling, which was based on voluntariness of the participants and institutions that were easily accessed by the researchers. Upon completion of the data collection, 300 security guards participated in the study. Several inclusion and exclusion criteria were listed and presented in the participant information sheet. The inclusion criteria were security guard of 20 to 59 years old, able to read and write on their own, and had no history of criminal conviction. The exclusion criteria included prior diagnosis of mental and physical health problems, history of criminal conviction, and history of substance abuse treatment.

\subsection{Instruments}

\subsubsection{Simple Screening Instrument for Alcohol and Other Drug (SSI-AOD)}

It is a screening instrument to asses both alcohol and drug use and to examine the symptoms of dependency for both substances. This instrument was developed by the Centre for Substance Abuse Treatment (CSAT) by incorporating selected screening items from 13 previously validated screening instruments [33]. The instrument contains 16 items that represent the following: consumption pattern; self-awareness of a problem; adverse physical psychological and social effects; and physiological effects of tolerance and withdrawal [34]. Higher score would demonstrate higher substance abuse. The test-retest reliability of the SSI-AOD is .97 , with sensitivity of $92 \%$ and overall accuracy of $81.9 \%$ [33].

\subsubsection{Carlson Psychological Survey-Antisocial Tendency scale (CPS-AT scale)}

The instrument was developed by Carlson (1982) based on the needs of offenders' population. The antisocial tendency scale is one of four scales incorporated into one psychological survey containing 50 items, with 16 items are related to antisocial tendency. The scale screens antisocial tendency behaviour of the respondent. Higher score would indicate higher tendency for antisocial behaviour. The reliability of the scale is .82 and test-retest reliability is .89 [35]. 


\subsubsection{McLean Screening Instrument for Borderline Personality Disorder (MSI-BPD)}

The instrument was developed by Zanarini and colleagues (2003) for screening of borderline personality disorder. It contains 10 items inquiring the common symptoms of borderline personality disorder, such as impulsivity, emotion instability, and unstable relationship. More positive symptoms indicate higher possibility for borderline personality disorder. Previous study finds that the instrument yields $81 \%$ sensitivity and $85 \%$ specificity [36].

\subsubsection{Center for Epidemiologic Study Depression scale (CES-D)}

It is a screening instrument to measure common symptoms of depression. The instrument, which contains 20 items using four-point Likert scale, was designed by Radloff (1977). The questions are related to certain depression symptoms such as poor appetite, sleep disturbance, and loss of concentration. Higher score would indicate higher level of depression. The CES-D has .85 to .90 internal consistencies [37].

\subsubsection{Aggression Questionnaire (AQ)}

The instrument, which was designed by Buss and Perry (1992), is a screening instrument for aggressiveness. With 29 items using five-point Likert scale, the instrument consists of 4 scales: physical aggression, verbal aggression, anger, and hostility. Each scale has different number of items. Higher score for each scale indicates higher tendency for the aggressive behaviour. The reliability of the $\mathrm{AQ}$ is .92 [38].

\subsection{Data Collection}

The data collection took place mostly at the workplace of the participants since the participants were approached during their working hour. The participants were asked with a few questions including their voluntary to participate in the study. As the participant agreed to take part in the study, a set of instruments including five questionnaires, a demographic information sheet, and participant information sheet was given to the participants. The participants were given option to complete the instruments in their convenience. Some participants completed the instruments and returned them to the researcher on the same time. The average time taken to complete all instruments was 20 minutes. Some others chose to take the instruments back with them and returned the completed instruments to the researcher on the next day. The return rate was $100 \%$ and the completion rate was $95 \%$.

\subsection{Analysis}

The collected data were systematically organised and analysed using SPSS version 19.0. Descriptive statistics were used to summarise the demographic information as well as the score for all variables. Upon screening of the exclusion criteria, the analysis proceeded with statistical analysis. To examine the relationship between mental health problems and aggression scales, simple linear regression was performed. The predictor variables were the types of mental health problems (substance abuse, antisocial tendencies, borderline personality disorder, depression) and the outcome variables were the aggression scales (physical aggression, verbal aggression, anger, hostility). Furthermore, to compare between the genders groups, independent $t$-test was run. The occurrence of the types of mental health problems was compared between male and female participants.

\section{Results}

\subsection{Demographic Information}

The participants were made up of $75 \%$ of males and $25 \%$ of females. Summary of the participants' demographic information is shown in Table 1. The distribution of the age group was fairly equal, with the highest age group was within the age range of 30 to 39 years old. Majority of the participants were Malay (83.7\%), married (68.7\%), and had their highest education at secondary level $(81.7 \%)$.

Table 1. Summary of participant's demographic information $(N=300)$

\begin{tabular}{|c|c|c|}
\hline Information & Frequency (n) & Percentage (\%) \\
\hline \multicolumn{3}{|l|}{ Gender } \\
\hline Male & 225 & 75.0 \\
\hline Female & 75 & 25.0 \\
\hline \multicolumn{3}{|l|}{ Age group } \\
\hline 20 to 29 & 75 & 25.0 \\
\hline 30 to 39 & 78 & 26.0 \\
\hline 40 to 49 & 77 & 25.7 \\
\hline 50 to 59 & 70 & 23.3 \\
\hline \multicolumn{3}{|l|}{ Ethnicity } \\
\hline Malay & 251 & 83.7 \\
\hline Chinese & 18 & 6.0 \\
\hline Indian & 19 & 6.3 \\
\hline Others & 12 & 4.0 \\
\hline \multicolumn{3}{|l|}{ Marital status } \\
\hline Single & 73 & 24.3 \\
\hline Married & 206 & 68.7 \\
\hline Divorcee & 18 & 6.0 \\
\hline Widow & 3 & 1.0 \\
\hline \multicolumn{3}{|c|}{ Highest education level } \\
\hline None & 2 & .7 \\
\hline Primary & 41 & 13.7 \\
\hline Secondary & 245 & 81.7 \\
\hline Tertiary & 12 & 4.0 \\
\hline
\end{tabular}

\subsection{Descriptive Results}

The level of substance abuse among the participants was low. Only about one-fifth of them indicated that they had abused substance. Males showed higher incidence of substance abuse compared to females. The descriptive results of the variables are tabulated in Table 2 . 
Table 2. Descriptive results of types of mental health problems and aggression scales

\begin{tabular}{|c|c|c|c|c|}
\hline \multicolumn{2}{|c|}{ Variables } & \multirow{2}{*}{$\begin{array}{c}\text { Male, n (\%) } \\
50(22.2)\end{array}$} & \multirow{2}{*}{$\begin{array}{c}\text { Female, n (\%) } \\
12(16.0)\end{array}$} & \multirow{2}{*}{$\begin{array}{c}\text { Total, n (\%) } \\
62(20.7)\end{array}$} \\
\hline Cubtom & Yes & & & \\
\hline substance abuse & No & $175(77.8)$ & $63(84.0)$ & $238(79.3)$ \\
\hline \multirow{2}{*}{ Antisocial tendencies } & Above mean & $105(46.7)$ & $35(46.7)$ & $140(46.7)$ \\
\hline & Below mean & $120(53.3)$ & $40(53.3)$ & $160(53.3)$ \\
\hline \multirow{2}{*}{$\begin{array}{c}\text { Borderline personality } \\
\text { disorder }\end{array}$} & Above mean & $70(31.1)$ & 37 (49.3) & $107(35.7)$ \\
\hline & Below mean & $155(68.9)$ & $38(50.7)$ & $193(64.3)$ \\
\hline \multirow{2}{*}{ Depression } & Above mean & $116(51.6)$ & $28(37.3)$ & $144(48.0)$ \\
\hline & Below mean & $109(48.4)$ & $47(62.7)$ & $156(52.0)$ \\
\hline \multirow{2}{*}{ Physical aggression } & Above mean & $76(33.8)$ & $20(26.7)$ & $96(32.0)$ \\
\hline & Below mean & $149(66.2)$ & $55(73.3)$ & $204(68.0)$ \\
\hline \multirow{2}{*}{ Verbal aggression } & Above mean & $110(48.9)$ & $41(54.7)$ & $151(50.3)$ \\
\hline & Below mean & $115(51.1)$ & $34(45.3)$ & $149(49.7)$ \\
\hline \multirow{2}{*}{ Anger } & Above mean & $101(44.9)$ & $35(46.7)$ & $136(45.3)$ \\
\hline & Below mean & $124(55.1)$ & $40(53.3)$ & $164(54.7)$ \\
\hline \multirow{2}{*}{ Hostility } & Above mean & $90(40.0)$ & $36(48.0)$ & $126(42.0)$ \\
\hline & Below mean & $135(60.0)$ & $39(52.0)$ & $174(58.0)$ \\
\hline
\end{tabular}

The presence of antisocial tendencies was considerably high among the participants with nearly half scored above the mean score $(M=28)$. Similarly, the incidence of borderline personality disorder was fairly high with more than quarter $(35.7 \%)$ of the participants scored above the mean score $(M=2)$. Females demonstrated higher positive response for borderline personality disorder compared to males. Depression was also found high among the participants, with nearly $50 \%$ of the participants scored above the mean score $(M=12)$. Males showed higher incidence of depression than females.

Presence of aggressive behaviours was notable among the participants. As shown in Table 2, considerably high number of participants scored above the mean score $(M=17)$ for physical aggression (32\%) and males scored higher than females. Half of the participants scored high for verbal aggression $(M=11)$ with females scored higher than males. In addition, nearly half of the participants scored above the mean score for anger $(\mathrm{M}=15)$ with males and females having almost similar figure. Fairly high number of participants scored above the mean score $(M=16)$ for hostility $(42 \%)$ with females scoring higher compared to males.

\subsection{Statistical Results}

Statistical comparison between male and female participants showed that only antisocial tendency was not significantly different between the gender groups. The results are shown in Table 3.

Table 3. The result of independent t-test between male and female participants

\begin{tabular}{ccccccccc}
\hline \multirow{2}{*}{ Variables } & \multicolumn{2}{c}{ Mean score } & \multicolumn{2}{c}{ Standard error mean } & \multicolumn{3}{c}{ Independent $\boldsymbol{t}$-test } \\
& Male & Female & Male & Female & $\boldsymbol{t}$ & $\boldsymbol{d}$ & $\boldsymbol{p}$-value \\
\hline Substance abuse & 1.18 & .67 & .13 & .12 & 2.89 & 247.15 & .004 \\
Antisocial tendencies & 28.11 & 27.52 & .41 & .61 & .741 & .298 & .424 \\
$\begin{array}{c}\text { Borderline personality } \\
\text { disorder }\end{array}$ & 1.24 & 2.03 & .11 & .27 & -2.68 & 100.6 & .009 \\
Depression & 12.54 & 10.64 & .42 & .61 & 2.35 & 298 & .019 \\
\hline
\end{tabular}

Substance abuse, borderline personality disorder, and depression were significantly different $(p<.025)$ between male and female participants in this study. Antisocial tendency, on the other hand, showed no statistical difference between male and female participants. Based on the mean score, males had significantly higher incidence of substance abuse and depression than females, whereas females had significantly higher incidence of borderline personality disorder than males. These findings indicated that male and female security guards have different incidence of certain types of mental health problems whereas other types of mental health problems may not be different between the gender groups.

Mental health problems showed significant relationship with the four scales of aggression (physical aggression, verbal aggression, anger, and hostility). The results are tabulated in Table 4. The relationships were particularly notable between the two subtypes of personality disorders and the aggression scales as almost all relationships were strongly significant $(p<.001)$. 
Table 4. Simple linear regression between types of mental health problems and aggression scales

\begin{tabular}{|c|c|c|c|}
\hline \multirow{2}{*}{ Variables } & \multirow{2}{*}{ Outcome variables } & \multicolumn{2}{|c|}{ Simple linear regression } \\
\hline & & $b(95 \% \mathrm{CI})$ & $p$-value \\
\hline \multirow{4}{*}{ Substance abuse } & Physical aggression & $.42(.08, .75)$ & .014 \\
\hline & Verbal aggression & $.32(.05, .58)$ & .020 \\
\hline & Anger & $.29(.05, .54)$ & .018 \\
\hline & Hostility & $.42(.03, .81)$ & .033 \\
\hline \multirow{4}{*}{ Antisocial tendencies } & Physical aggression & $.13(.03, .23)$ & .010 \\
\hline & Verbal aggression & $.15(.07, .23)$ & $<.001$ \\
\hline & Anger & $.20(.13, .27)$ & $<.001$ \\
\hline & Hostility & $.21(.10, .33)$ & $<.001$ \\
\hline \multirow{4}{*}{ Borderline personality disorder } & Physical aggression & $.30(-.02, .62)$ & .070 \\
\hline & Verbal aggression & $.49(.23, .74)$ & $<.001$ \\
\hline & Anger & $.47(.24, .70)$ & $<.001$ \\
\hline & Hostility & $.70(.33,1.07)$ & $<.001$ \\
\hline \multirow{4}{*}{ Depression } & Physical aggression & $.11(.01, .21)$ & .030 \\
\hline & Verbal aggression & $.08(-.00, .16)$ & .061 \\
\hline & Anger & $.16(.08, .23)$ & $<.001$ \\
\hline & Hostility & $.29(.17, .40)$ & $<.001$ \\
\hline
\end{tabular}

As shown in Table 4, only two relationships were not significant $(p>.05)$, which are between borderline personality disorder and physical aggression, and between depression and verbal aggression. All other relationships were significant. The borderline personality disorder and antisocial tendencies showed particularly strong association with aggressive behaviours among the security guards, suggesting that personality disorders are the main contributor towards aggression among security guards. Antisocial tendencies showed significant contribution to physical aggression, verbal aggression, anger, and hostility, whereas borderline personality disorder demonstrated significant contribution towards verbal aggression, anger, and hostility. Borderline personality disorder however did not lead to physical aggression.

In addition, substance abuse and depression demonstrated some significant relationships with aggression scales but with lesser strength compared to the personality disorders. Substance abuse was significantly associated with all the aggression scales. Similarly, depression was associated with all the scales, except with verbal aggression. These findings suggested that depression may lead to aggressive acts among security guards but not to verbal aggression. Overall, the findings demonstrated the significant contribution of mental health problems towards aggressiveness among the participants in the current study.

\section{Discussions}

The modern needs for a more secure living condition have led security-related profession to be one of the fastest growing professions worldwide [7-8]. However, in fulfilling the needs, the prevalence of several types of mental health problems among the security guard, as found in the current study, highlights the presence of risk factors for possible consequences, particularly the negatives one. It is important to emphasise on the well-being of a person who works as a security personnel, especially on their mental well-being. Certain types of mental health problems, for example antisocial personality disorder, may result in negative effects such as incidence of violence at work. It is particularly essential to minimise the presence of risk factors leading to negative consequences to prevent work-related violence, especially among those in security profession.

Being in security-related profession, especially those who work as a security guard, requires frequent contact with many people while bearing their expectation and reliance. The scope of the job itself demands an individual working as a security guard to be completely healthy, both physically and mentally. For an instance, substance abuse may render an individual to various misconducts during work, such as intoxication and negligence. This was evidenced at an international airport where two security guards were drunk and fell asleep when they were working [7]. In the current study, substance abuse, personality disorder, and depression were found significant among the security guards. Considering the seriousness of the case and the population of interest, the presence of each type of mental health problems is notable, with depression and antisocial personality disorder being particularly high. Being the possible risk factors for work-related violence or other negative consequences, the findings mark the requirement for proper screening of individual's mental well-being before being employed as security personnel. It is possible that the security guards involved in this study are unaware of their problems and some might need evaluation from experts to confirm the problems so that proper treatment could be proposed. In addition, evidence of mental health problems may inaugurate the assessment and management of violence risk [39]. 
Moreover, in the current study, the presence of aggressive behaviours was notable among the security guards. Verbal aggression was identified as the most common form of aggressive behaviour among them while physical aggression was the least common. Nevertheless, the findings showed the tendencies for the security guards to engage in aggressive acts when triggered or necessary. Based on the percentage of those who scored high for each scale, the security guards involved in the current study were likely to be verbally aggressive rather than physically. In addition, some showed tendency to become angry or hostile towards others. These may be caused by the job itself, which is often taken lightly by others and usually does not have high pays. These findings highlight the possible risk for aggressive acts among the security guards and thus recommend subsequent measures. To assure the well-being of security guards at work as well as to prevent possible negative consequences, the employer should regularly organise specific programme such as anger management and self-esteem therapy for the employees [17].

Male and female security guards showed significant difference in occurrence of each type of mental health problems. Based on the mean score, males showed higher level of substance abuse, antisocial tendencies, and depression, while female showed higher level of borderline personality disorder. However, antisocial tendencies were not significantly different between the gender groups, indicating that both males and females had the same tendency for antisocial behaviour. On the other hand, substance abuse and depression were significantly higher among male security guards, while borderline personality disorder was higher among female security guards. These findings demonstrated type of mental health problems that may be present at different levels between male and female security guards. In addition, these findings can be helpful in finding the possible risk factors for aggressive behaviours in male and female security guards.

The association between mental health problems and aggressive behaviours has long been suggested [28-29, 31-32]. The current findings supported the postulation where the four subtypes of mental health problems were found significantly related to the four scales of aggression. With exception to two insignificant relationships, substance abuse, antisocial tendencies, borderline personality disorder, and depression demonstrated significant contribution towards the aggressive acts physically, verbally or internally (being angry or hostile) among the security guards. Apparently, these findings indicated potential insecurity towards the safety of people being protected. The findings also demonstrated the negative consequence of mental health problems among the security guards, which suggested that they might not fit to be security guards.

Some contradictions were found. Borderline personality disorder showed no significant relationship to physical aggression, which indicated that the personality disorder was not a factor for physical aggressive act among the security guards in this study. Other than that, depression showed no significant relationship to verbal aggression, indicating that being depressed may not lead to verbal aggressive act among the security guards. Nevertheless, mental health problems were strongly suggested as the risk factors for involvement of security guards in aggressive acts. These findings further supported the importance of the mental well-being among security guards in order to achieve the ideal secure and safe working environment.

Identification of mental health problems and aggressive acts among security guards in the current study indicated presence of possible risk factors that may jeopardise the safety of their working environment as well as people in the environment. Personality disorders showed the highest risk towards occurrence of aggression among security guards, which demonstrated that security guards with personality disorders were not totally safe. These findings suggested that the employer should avoid taking people with personality disorders as their security guards. Otherwise, security guards with personality disorders should undergo proper therapy that could help them suppress their problems during work. In addition, significant associations between substance abuse and depression with aggression among the security guards also suggested that security guards with both problems were not totally safe for their purpose of work. Therefore, people who had involved with substance abuse or had suffered severe depression should not be working as security guards so that the risk of workplace violence could be minimised.

\section{Conclusion}

Based on the significant presence of substance abuse, antisocial tendencies, borderline personality disorder, and depression among security guards in the current study, the four subtypes of mental health problems were identified as possible risk factors for workplace violence among the security guard. In addition, four types of aggressive behaviours were found significant among the security guards. Furthermore, statistical analysis that showed the significant contribution of the four subtypes of mental health problems towards the four scales of aggression confirmed that mental health problems are possible risk factors for workplace violence among them. These findings support that people who work as security guards are not totally safe in the presence of mental health problems. Moreover, male and female security guards showed significant difference in presence of mental health problems, except for antisocial tendencies, indicating that presence of mental health problems may be different between gender groups. The current findings suggested that more in-depth studies focusing on security-related profession should be conducted in consideration of the significance of this profession towards a secured and protected environment. Public awareness of the issues especially among the employers should be pervasive so that it can be helpful as the preventive measures, and therefore, in establishment of well-being at work. 


\section{Acknowledgements}

The authors would like to address special thanks to Universiti Sains Malaysia for supporting this study, and to all participants for giving a kind cooperation.

\section{References}

[1] T. Leino, R. Selin, H. Summala, and M. Virtanen, "Work-related violence against security guards - Who is most at risk?" Ind. Health, vol. 49, pp. 143-150, December 2011.

[2] H. D. Harvey, P. Fleming, and D. Mooney, "Violence at work: An initial needs assessment for the environmental health department as a health promoting workplace," JEHR, vol. 1, pp. 41-49, 2002.

[3] T. Carmi-Iluz, R. Peleg, T. Freud, and P. Shwartzman, "Verbal and physical violence towards hospital- and community-based physicians in the Negev: An observational study,” BMC Health Serv. Res., vol. 5, Research article, August 2005.

[4] B. Beech and P. Leather, "Workplace violence in the healthcare sector: A review of staff training and integration of training evaluation models," Aggress. Violent Beh., vol. 11, pp. 27-43, August 2006.

[5] J. Wieclaw, et al., "Work related violence and threats and the risk of depression and stress disorders," J. Epidemiol. Community Health, vol. 60, pp. 771-775, September 2006.

[6] F. Declercq, S. Vanheule, S. Markey, and J. Willemsen, "Posttraumatic distress in security guards and the serious effects of social support," J. Clin. Psychol., vol. 63, pp. 1239-1246, December 2007.

[7] H. Born, M. Caparini, and E. Cole, "Regulating private security companies in Europe: Status and prospects," Policy Paper no.20, Geneva Centre for the Democratic Control of Armed Forces, 2007.

[8] T. Prenzler, K. Earle, and R. Sarre, "Private security in Australia: Trends and key characteristics," Trends \& Issues in Crime \& Criminal Justice, no. 374. Canberra, Australia: Australian Institute of Criminology, 2009.

[9] E. E. Joh, "The paradox of private policing," J. Crim. Law Crim., vol. 95, pp. 49-131, 2004.

[10] M. Kempa, P. Stenning, and J. Wood, "Policing communal spaces: A reconfiguration of the 'Mass Private Property' hypothesis,” Brit. J. Criminol., vol. 44, pp. 562-581, April 2004.

[11] R. H. Moore Jr., "Civil liability for negligent and inadequate training: A private security problem," J. Contemp. Crim. Just., vol. 4, pp. 106-118, May 1988.

[12] V. Di Martino, H. Hoel, and C. L. Cooper, "Preventing violence and harassment in the workplace," Dublin, Ireland: European Foundation for the Improvement of Living and Working Conditions, 2003.

[13] L. Alfredsson, T. Akerstedt, M. Mattsson, and B. Wilborg, "Self-reported health and well-being amongst night security guards: A comparison with the working population," Ergonomics, vol. 34, pp. 525-530, May 1991.
[14] B. Grosswald, "The effects of shift work on family satisfaction," Fam. Soc., vol. 85, pp. 413-423, 2004.

[15] S. M. Jex and P. D. Bliese, "Efficacy beliefs as a moderator of the impact of work-related stressors: A multilevel study," J. Appl. Psychol., vol. 84, pp. 349-361, June 1999.

[16] T. Leino, "Work-related violence and its associations with psychological health: A study of Finnish police patrol officers and security guards," Helsinki, Finland: Finnish Institute of Occupational Health, 2013.

[17] B. Kucera, "Discussion paper on workplace aggressive behaviour and bullying," East Perth, Western Australia: The Workplace Aggressive Behaviour and Bullying Working Party, Minister for Health, 2003.

[18] C. S. Dewa, A. Lesage, P. Goering, and M. Caveen, "Nature and prevalence of mental illness in the workplace," Healthc. Pap., vol. 5, pp. 12-25, October 2004

[19] U. R. Srivastava, "Shift work related to stress, health and mood states: A study of dairy workers," Journal of Health Management, vol. 12, pp. 173-200, July 2010.

[20] L. C. C. Cheung, H. W. H. Tsang, and C. U. Tsui, "a job-specific social skills training program for people with severe mental illness: A case study for those who plan to be a security guard,” J. Rehabil., vol. 72, pp. 14-23, October 2006.

[21] J. A. Silva, G. B. Leong, and R. Weinstock, "Psychotic patient as security guard," J. Forensic Sci., vol. 38, pp. 1436-1440, November 1993.

[22] N. Ogińska-Bulik, "The role of personal and social resources in preventing adverse health outcomes in employees of uniformed professions,” Int. J. Occup. Med. Environ. Health, vol. 18 , pp. 233-240, July 2005 .

[23] M. Jamal, "Burnout, stress and health of employees on non-standard working schedules: A study of Canadian workers," Stress Health, vol. 20, pp. 113-119, August 2004.

[24] K. Kogi, "International research needs for improving sleep and health of workers," Ind. Health, vol. 43, pp. 71-79, January 2005

[25] M. Jakupcak, et al., "Anger, hostility, and aggression among Iraq and Afghanistan war veterans reporting PTSD and subthreshold PTSD," J. Trauma. Stress, vol. 20, pp. 945-954, December 2007.

[26] M. Tull, "Constructive vs. destructive anger in PTSD," November 2012. Retrieved from: http://ptsd.about.com/od/relatedconditions/a/PTSDanger.htm

[27] World Health Organization, "Mental health: A state of well-being," October 2011. Retrieved from: http://www.who.int/features/factfiles/mental health/en/index.html

[28] D.M. de Barros and A. de Pádua Serafim, "Association between personality disorders and violent behavior," Forensic Sci. Int., vol. 179, pp. 19-22, April 2008.

[29] C. Logan and R. Blackburn, "Mental disorder in violent women in secure settings: Potential relevance to risk for future violence," Int. J. Law Psychiatry, 32, 31-38, January to February 2009.

[30] T.D. Gunter, "Incarcerated women and depression: A primer for the primary care provider," J. Am. Med. Womens Assoc., vol. 59, pp. 107-112, 2004. 
[31] L. Citrome and J. Volavka, "Treatment of violent behavior," in Psychiatry, $2^{\text {nd }}$ ed., A. Tasman, J. Kay, and J. Lieberman, Eds. New York: John Wiley \& Sons, 2003, Chapter 103.

[32] C. L. Scott and P. J. Resnick, "Violence risk assessment in persons with mental illness," Aggress. Violent Beh., vol. 11, pp. 598-611, May 2006.

[33] R. H. Peters, et al., "Effectiveness of screening instruments in detecting substance use disorders among prisoners," J. Subst. Abuse Treat., vol. 18, pp. 349-358, June 2000.

[34] Center for Substance Abuse Treatment (CSAT), "Simple Screening Instruments for Outreach for Alcohol and Other Drug Abuse and Infectious Diseases: Treatment Improvement Protocol Series 11," Washington, DC: US Government Printing Office. Publication (SMA) 95-3058, 1994.
[35] K. A. Carlson, "Carlson Psychological Survey manual," Port Huron, Michigan: SIGMA Assessment Systems, Inc., 1982.

[36] M. C. Zanarini, et al., "A screening measure for BPD: The McLean Screening Instrument for Borderline Personality Disorder (MSI-BPD)," J. Personal. Disord., vol. 17, pp. 568-573, December 2003.

[37] L. S. Radloff, "The CES-D scale: A self-report depression scale for research in the general population," Appl. Psych. Meas., vol. 1, pp. 385-401, June 1977.

[38] A. H. Buss and M. Perry, "The Aggression Questionnaire," J. Pers. Soc. Psychol., vol. 63, pp. 452-459, April 1992.

[39] A. Maden, Treating violence: A guide to risk management in mental health, Oxford: Oxford University Press, March 2007. 